or ton early, in the only proper articles of diet and drink, as above specified, by allowing nature a fair opportunity of restoring, by the digestion of appropriate aliment, that physical strength which, as a necessary consequence of the disease, has been lost, it is true the sick may require a few more days of repose or inaction, but it is still more true that by such a proceeding the progress towards a state of health will be more regular and more certain, with scarcely the possibility of a relapse or drawback. To get out of bed 100 soon, to walk aboul the room, or to go into the street for exercise, without having previously gained a cerlain amount of strength, have too often proved that even after having passed through the disease and been brought to the stage of convalescence, not a few verify the truth of the trite adage, "the more haste, the worse speed," a fatal result frequently ensuing.

In conclusion, I would state that the aqua lanro cerasi, used in the hospital, is a substitute made by adding one drop and a half of the oil of bitter almonds to an ounce of water, making the mixture secundem artem. In private practice I am accustomed to use the orange flower water in its stead.

\title{
EXCISION OF THE ELBOW-JOINT IN A CASE OF LACERATED
} WOUND OF THE ARTICULATION.

BY O. KIMBaI.L, M.D., I.OWEJL, MASS.

[Reported for the Boston Medical and Surgicel Journal hy E. K. SA non, M.D.]

IT is to the credit of modern surgeons that the highest honors of their art are gathered from the field of "conservative surgery." The saving of a life and a limb at the sacrifice of a joint, is a real triumph, and every instance of success which illustrates this great modern improvement in surgery is worthy of record. The following case occurred under the care of Dr. Kimball during the past year.

On the 3rd of June last, W. F., a strong, healihy young man, 24 years old, was employed about a "derrick" in repairing a railroad bridge in this city. By some accident his elbow was caught bet iveen livo pointed chain hooks, which transfixed the joint, and tore out, in such a manner as to open the articulation completely and leave the articular surfaces of the humerus and ulna protruding. 'The head of the radius was broken off, which was all the injury done to the bones themselves. The triceps extensor muscle was also torn off from its attachment to the ulna, and lacerated in a considerable extent; and the injury generally done to the soft parts was very extensive.

The engraving on the next page represents the appearance of the arm at this time. On examination it was found that the attacliment of the biceps to the tubercle of the radius was uninjured. Also that the brachialis anticus was still attached to the ulna. The blood-vessels and nerves were also uninjured. Under these cir- 
cumstances, the decision to allempt to preserve the limb with the loss of the joint was quickly made. The chain saw was applied to the humerus, just above the condyles, which were thus removed.

As much of the ulna and ra. dius were removed as could be with safety to the atlachments of the brachialis anlicus and biceps. About an inch of the triceps extensor was then removed; also an amount of contused and lacerated soft tissue, in order to give the injury, as far as possible, the character of an incised wound. 'The edges of the wound then being brought together by sutures and adhesive straps, the limb was

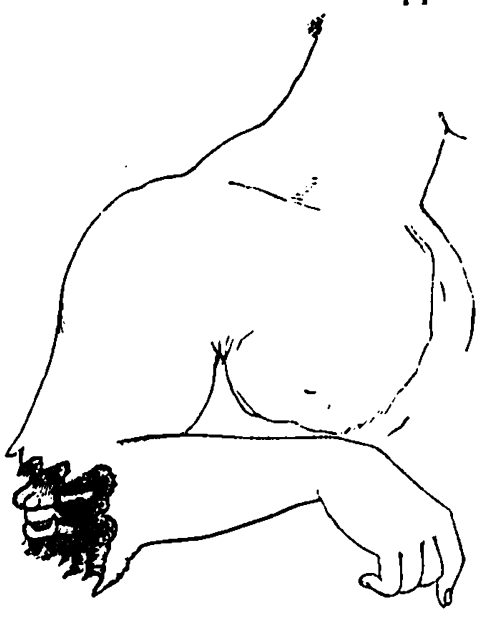
placed in a splint, in the straigltt position, and the simple "water dressing" used. No unfavorable symptom appeared, and at the end of six weeks the wound had entirely closed, and a flexible union had taken place between the ends of the bones.

At this time an angular splint was applied, and passive motion kept up for a number of weeks. In the course of the summer the splint was removed, and the arm, bent at a right angle, waskept in a sling. During this time there was an obstinate tendency to solidification in the false joint, and at inlervals of two or three weeks it was found necesssary to give chloroform and restore the movements of the new joint, by forcible flexion and extension.

The present appearance of the arm is shown in the annexed engraving, taken three weeks since. The power of bending the arm is preserved to a useful extent. The motions of the fingers and wrist are perfect. The power of extension is impaired, but not lost; and the chief defect in the motions of the arm is the limited power of

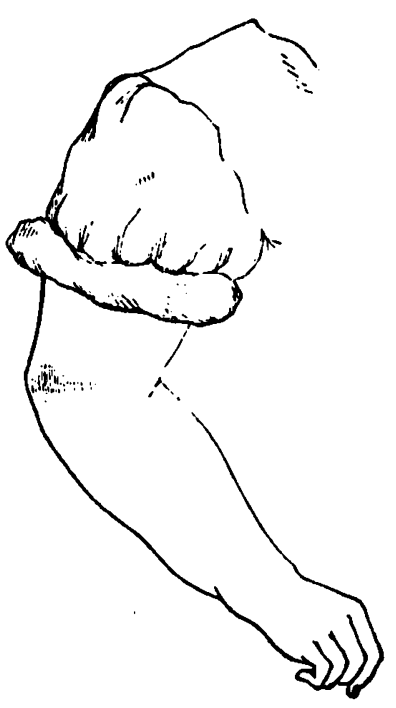
pronation and supination.

As evidence of the usefulness of the arm, it may be stated that the man is now at work for the railroad company, and is able to do his day's work, at shovelling gravel or snow, without difficulty. 